\title{
Influence of Primers on the Optical Characteristics of Ink-Jet Imprints
}

\author{
Svitlana HAVENKO*, Svitlana KHADZHYNOVA**, Konrad OLEJNIK***, \\ Edmundas KIBIRKŠTIS*****, Kęstutis VAITASIUS****** \\ *Lodz University of Technology, Wolczanska 223, 90-924 Lodz, Poland, E-mail: svitlana.havenko@p.lodz.pl \\ **Lodz University of Technology, Wolczanska 223, 90-924 Lodz, Poland, E-mail: svitlana.khadzhynova@ p.lodz.pl \\ ***Lodz University of Technology, Wolczanska 223, 90-924 Lodz, Poland, E-mail: konrad.olejnik@ p.lodz.pl \\ ****Kaunas University of Technology, Department of Manufacturing Engineering, Studentu St. 56, LT-51424, Kaunas, \\ Lithuania,E-mail: edmundas.kibirkstis@ktu.lt \\ *****Kaunas University of Technology, Department of Manufacturing Engineering, Studentu St. 56, LT-51424, Kaunas, \\ Lithuania, E-mail: kestutis.vaitasius@ktu.lt
}

cross $^{\text {ref }}$ http://dx.doi.org/10.5755/j01.mech.26.4.24434

\section{Introduction}

Today, digital printing duly took its niche in the market of printing and packaging products. And this is due in the first place to the fact that the quality of imprints of modern digital machines is not inferior to the quality of offset printing. The quality of ink-jet printing depends to a large extent on the technical characteristics of the selected equipment and the surface properties of the printed substrates. It is known that for digital printing it is necessary to use expensive paper with a special coating that determines the degree of gloss of the surface. Therefore, ordinary offset papers before ink-jet printing are covered with primers that ensure good fixation of pigment ink or dye on paper, a wide field of color coverage, characteristic gloss, which generally contribute to high quality of imprints [1$3]$. Problems of quality of digital printing attracted the attention of many researchers. Thus, printing quality on inkjet printers was investigated by Buczynski L. [4]. Two mechanisms of interaction of ink with a substrate in digital printing are described in his writings by Le H.P. [5]. When attached to the substrate of dye inks, the dye molecules dissolve in a solvent that deeply penetrates or absorbed by a paper lining and its coating. In the case of fixation of pigment ink, the pigment particles are dispersed in a solvent. In this case, the ink-binding substance penetrates deeply into the paper substrate, and pigment particles tend to remain on the surface of the paper.

The type of used ink will depend on the type and properties of the printed substrate. In turn, the type of ink, its properties and the interaction with the substrate will depend on the thickness of the ink layer, which determines the quality of the image, especially in the color printing. When using liquid ink, the thickness of the ink layer is 0.5 microns. Digital printing often uses cheap and environmental water-based inks. The behavior of a droplet of water-based ink on paper is investigated by Magdassi S. [6]. During the first $\sim 10 \mu$ s from the contact of droplets with the primer, the initially spherical form of droplets changes, stretches and remains convex on the edges. After the next $\sim 20-80 \mu \mathrm{s}$, the drop reaches a static shape, having an approximate diameter of the final size of the printed image element, then it begins to compress, penetrating into the substrate, and evaporates. The fraction of the individual steps depends on the chemical composition of the ink and the climatic conditions, primarily on the temperature. Con- firmed, that obtaining high-quality printing with waterbased ink requires the use of special coatings on substrates. The mechanism of interaction of ink droplets with different paper substrates and bases is investigated in the writings of Lavery A., Provost J. [7] and shown in Fig. 1.

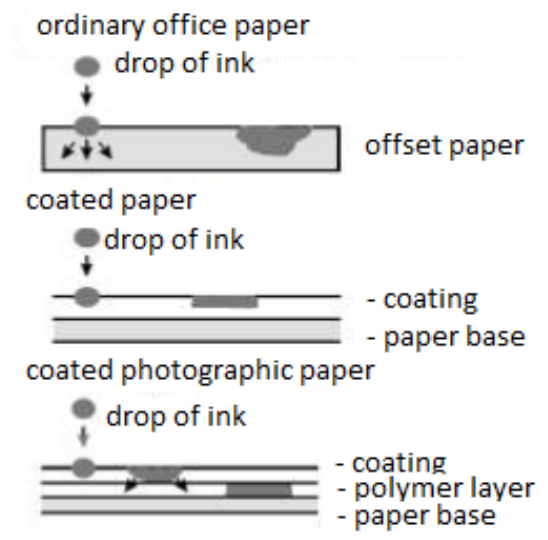

Fig. 1 A model of the behavior of the ink droplet depending on the type of paper [7]

The specificity of digital printing and the number of quality related issues are driving the control over a large number of print options. Among these parameters one can distinguish the following groups that determine the quality of the imprints: 1) the quality of the imprints performed by different types of inks, 2) the quality parameters of the printed line, 3 ) the quality of multicolored images overlaying, 4) the quality of the introduction in the two-sided printing, 5) the same imprints quality in circulation boundaries [8]. The influence of surface properties of offset paper on the quality of digital droplet-jet printing was investigated in [9]. As you can see, the type of the substrate and the state of its surface has a very great influence on the quality of the imprints. Therefore, the aim of the research was to study the effects of developed primers applied to ordinary offset and coated paper on the imprint quality of digital droplet inkjet printing.

\section{Objects and methods of research}

As objects of research were used imprints in the format of $210 \times 297 \mathrm{~mm}$ on offset papers with a grammar of $80 \mathrm{~g} / \mathrm{m}^{2}$ and coated papers with a grammar of $170 \mathrm{~g} / \mathrm{m}^{2}$, on 
the surface of which primers were applied before the printing. The imprints were received on an Epson Stylus Photo 1410 printer, where the black ink was pigmented, and colored (CMY) - dye, the minimum drop size was $1.5 \mathrm{pl}$; the configuration of the machine included 90 nozzles on color, the technology of photographic ink Claria; print resolution of 5,760×1,440 DPI. The paper was primed before printing. The primers were obtained on the basis of polyvinyl alcohol (PVS) interpolymeric complexes of the brand SUNDY PVA 088-20 of the Chinese firm "SinopecSichuanVinylon Works" (PVA 088-20 - $23 \mathrm{mPa} \cdot \mathrm{sec}$ ) with an optimal concentration of polyvinyl pyrrolidone with a molecular weight of $12,000 \pm 2600$. Interpolymeric complexes are obtained in aqueous solutions at different concentrations of PVA (from $10 \%$ to $16 \%$ by weight). Characteristics of the primers are given in Table 1.

Table 1

Characteristics of primers

\begin{tabular}{|c|c|c|}
\hline No. & $\begin{array}{c}\text { Concentration of } \\
\text { PVA, } \%\end{array}$ & $\begin{array}{c}\text { Surface tension, } \\
\sigma \times 10^{3}, \mathrm{~J} / \mathrm{m}^{2}\end{array}$ \\
\hline 1 & 10 & 57.9 \\
\hline 2 & 12 & 55.5 \\
\hline 3 & 14 & 54.3 \\
\hline 4 & 16 & 53.5 \\
\hline
\end{tabular}

The goniometer PGX (Thwing-Albert Europe) was used to measure the wetting angle. In the research, the mode of static measurement was selected with the ability to measure 10 images per minute and measuring time - 30 seconds. Distilled water drops were applied to the surface of the test sample using a micropump integrated with the capillary. The kinetics of penetration of liquid (distilled water) into a paper structure without a primer and with an applied primer is investigated using the Emtec PDA device. The principle of operation of the REA apparatus is based on the change in the intensity of the ultrasound signal, directed to the paper sample at the same time as the penetration of the liquid into its structure. A piece of paper is attached by a two-sided self-adhesive tape on a plastic plate and immersed in a certain liquid. When the sample is immersed in its direction, an ultrasound signal is sent from the transmitter at a frequency of 1 or $2 \mathrm{MHz}$ (in tests the frequency of $2 \mathrm{MHz}$ was used). This signal goes to the other side of the plate with a receiver with high sensitivity, and the change in the intensity of the ultrasound signal is processed by the computer. With the PDA device the following parameters were measured:

- $t_{\max }$ - is the time in which the intensity of liquid infiltration into the paper structure reaches a maximum [s],

- $t_{95}$ - the time after which the intensity of penetration decreased to $95 \%$ [c],

- $W$ - the wetting phase,

- A30 and A60 - equivalent grades of paper sizing $\mathrm{Cobb}_{30}$ and $\mathrm{Cobb}_{60}$.

The result of the measurements were graphs of the intensity of the liquid penetration into the structure of the paper from the moment of penetration and derivatives of graphs showing the uniformity of the liquid penetration into the paper relative to the position of the sensor [10].

To determine the optical density and measure the color characteristics of the imprint used device X-RITE 528 [11]. The quality of the imprints was also evaluated by such a parameter as mottle. Mottle (spotting) - a printing defect, which manifests itself in the uniqueness or heterogeneity of the printed area in the form of a printed spot or raster field and can be evaluate visually [12]. Determining this parameter for digital imprints is very important, because the mechanism of creating a digital image can often cause the phenomenon of spotting.

The uniformity of printing (spotting and graininess) was determined according to ISO/IEC 13660 and ISO/IEC TS 24790 standards. The ISO/IEC TS 24790: 2017 standard, as well as ISO/IEC 13660: 2001 (now replaced by ISO/IEC TS 24790), determine heterogeneity digital printing in two intermeshes: on a micro scale, the heterogeneity is called grainy, and at the macro level it is like spotting. The determination of these parameters ISO 13660 is to study a measurement area of at least a dimension of $161 \mathrm{~mm}^{2}$ (square area with dimensions $\geq 12.7 \times 12.7 \mathrm{~mm}$ ). This area is divided into at least 100 identical squares, which do not overlap each other with an area of at least $1.61 \mathrm{~mm}^{2}$ (one square cell with dimensions of $1.27 \times 1.27 \mathrm{~mm}$ ) [13].

\section{Research results}

Investigation of the depth of liquid (water) penetration into the structure of the paper surface showed that the presence of primer on the papers surface significantly affects the change in the wetting phase (Fig. 2). The coated paper, due to the fact that it is glued to the mass, creates resistance to penetration of water during the first stage of wetting and the phase of wetting is $W=0.78$, and the time of reaching the maximum intensity is 0.6 seconds.

On offset papers with a primer, the wetting phase $W=0$, and when the paper is immersed in water, there comes an instant implementation of maximum penetration $\left(t_{\max }\right)$ and a decrease in the intensity of wetting to $95 \% t_{\max }$ $\left(t_{95}\right)$. Thus, the presence of the primer accelerates (improves) the process of wetting of the paper surface. In the second stage it was discovered that the presence of the primer prevents excessive penetration of water into the paper structure, as evidenced by the steep inclination of the penetration curve and by $50 \%$ - 35\% lower value of $A 60$ (equivalent to Cobb60).

On coated papers, the primer had a decisive influence on the nature of the curves of water penetration into the paper structure. The presence of the primer completely changed the curves of water penetration into coated paper with primer $(10 \%, 12 \%, 14 \%$, and $16 \%$ PVA+PVP) during penetration (Fig. 3).

The process of water penetration into a paper without a primer takes place in two stages: in the beginning the paper creates a small resistance to the penetrating liquid $\left(t_{\max }=2.24\right.$, phase of wetting $\left.W=0.31\right)$, and in the second stage (upon reaching the maximum intensity of penetration) dynamically decreases. For papers covered with a primer, it is possible to distinguish three stages of the process of liquids penetration in their structure: the first stage is characterized by the absence of the wetting phase, that is, the paper with the primer does not create resistance to liquid penetration at this stage and the curve of the penetration begins to slowly fall from the starting. The next second stage at the time of 5-6 s begins to grow and reaches its second point of maximum (at about 30-40 s), and then again begins to decrease gradually. 


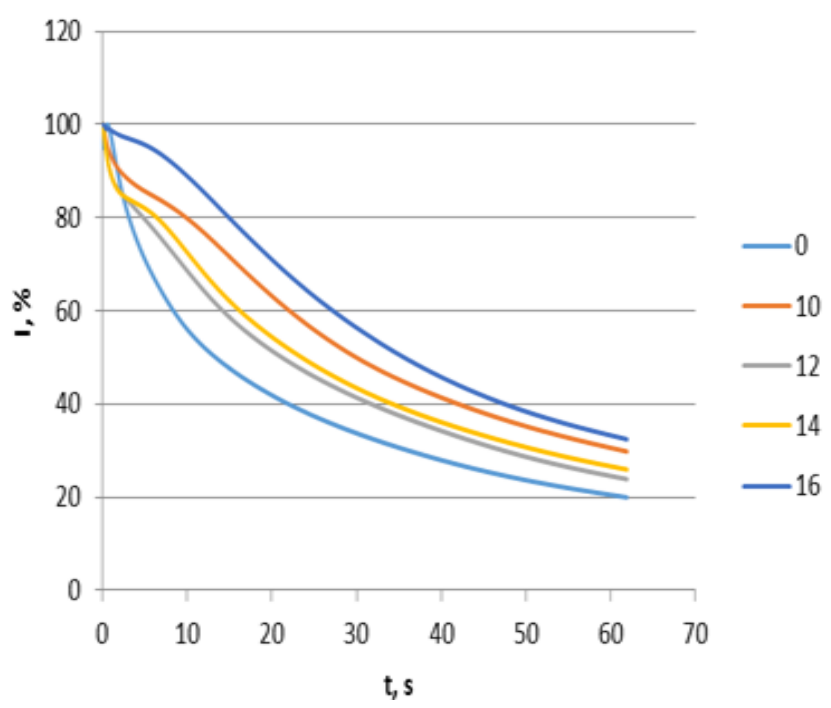

a

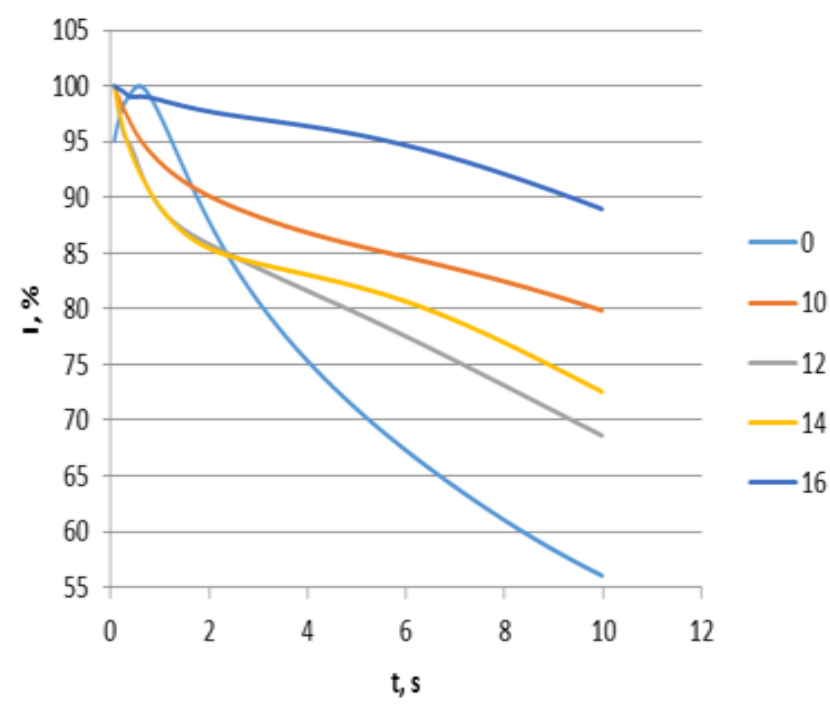

$\mathrm{b}$

Fig. 2 Dynamics curves of water penetration in the offset paper structure $\left(80 \mathrm{~g} / \mathrm{m}^{2}\right)$ without a primer and with a primer: a) penetration curves in time $60 \mathrm{~s} ; \mathrm{b}$ ) enlarged fragment of the penetration dynamics curve in time $10 \mathrm{sec}$

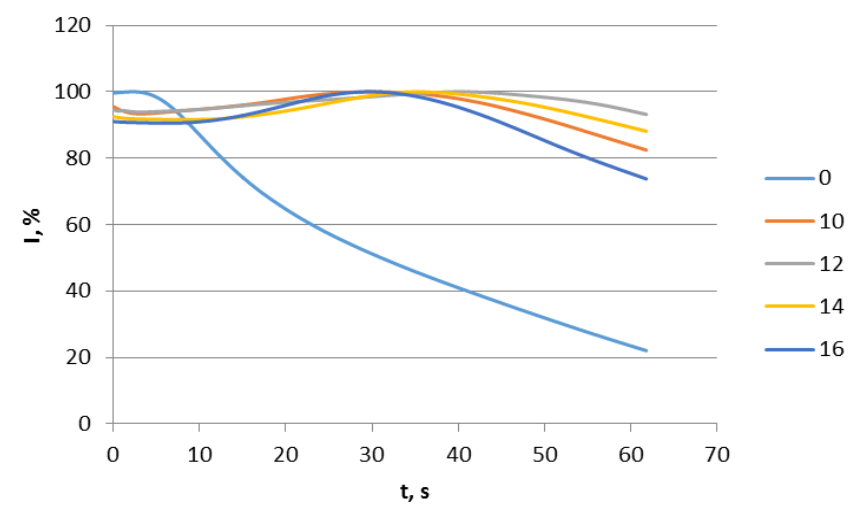

Fig. 3 Dynamics curves of water penetration into coated paper $\left(170 \mathrm{~g} / \mathrm{m}^{2}\right)$ without a primer and with a primer
This curve is inherent in some photographic papers designed for digital ink-jet printing. This penetration process allows the ink to be positioned near the paper surface / primer, which provides high printing intensity (high values of optical density). Using the studied primers, similar effects were obtained, which is confirmed by measurements of optical density on the imprints.

The study of the effect of the primer on the basis of modified PVA on the optical density of the imprints showed that the presence of the primer on offset and coated papers caused a significant increase in the intensity of the printing. The optical density in the presence of primers increased by about $40 \%$ on offset paper and more than $70 \%$ on coated paper (Table 2).

Impact of the primer on the optical density of the digital imprints (Magenta color)

\begin{tabular}{|c|c|c|c|c|c|}
\hline \multicolumn{6}{|c|}{ Optical density of drop ink-jet imprints } \\
\hline Concentration of PVA, $\%$ in the primer & 0 & 10 & 12 & 14 & 16 \\
\hline Offset paper $\left(80 \mathrm{~g} / \mathrm{m}^{2}\right)$ & 0.94 & 1.42 & 1.42 & 1.42 & 1.62 \\
\hline Coated paper $\left(170 \mathrm{~g} / \mathrm{m}^{2}\right)$ & 1.06 & 1.83 & 1.75 & 1.75 & 1.64 \\
\hline
\end{tabular}

Figs. 4-6.

Results of measurements of mottle and graininess on the imprint (Cyan color) are given in Table 3 and in

Parameters of Mottle and Graininess of imprint (Cyan color)

\begin{tabular}{|c|c|c|c|}
\hline $\begin{array}{c}\text { Type of } \\
\text { paper }\end{array}$ & $\begin{array}{c}\text { Primer } \\
\text { availability }\end{array}$ & $\begin{array}{c}\text { Mottle, } \\
\%\end{array}$ & $\begin{array}{c}\text { Graininess, } \\
\%\end{array}$ \\
\hline \multirow{4}{*}{ offset } & $\begin{array}{c}\text { without a } \\
\text { primer }\end{array}$ & 1.97 & 3.38 \\
\cline { 2 - 4 } & $10 \%$ & 1.4 & 3.65 \\
\cline { 2 - 4 } & $12 \%$ & 1.36 & 4.42 \\
\cline { 2 - 4 } & $14 \%$ & 1.30 & 3.78 \\
\cline { 2 - 4 } & $16 \%$ & 0.96 & 3.63 \\
\hline \multirow{5}{*}{ coated } & $\begin{array}{c}\text { without a } \\
\text { primer }\end{array}$ & 0.95 & 1.27 \\
\cline { 2 - 4 } & $10 \%$ & 1.45 & 4.02 \\
\cline { 2 - 4 } & $12 \%$ & 1.25 & 4.20 \\
\cline { 2 - 4 } & $14 \%$ & 1.15 & 2.70 \\
\cline { 2 - 4 } & $16 \%$ & 0.96 & 3.66 \\
\hline
\end{tabular}

Table 3

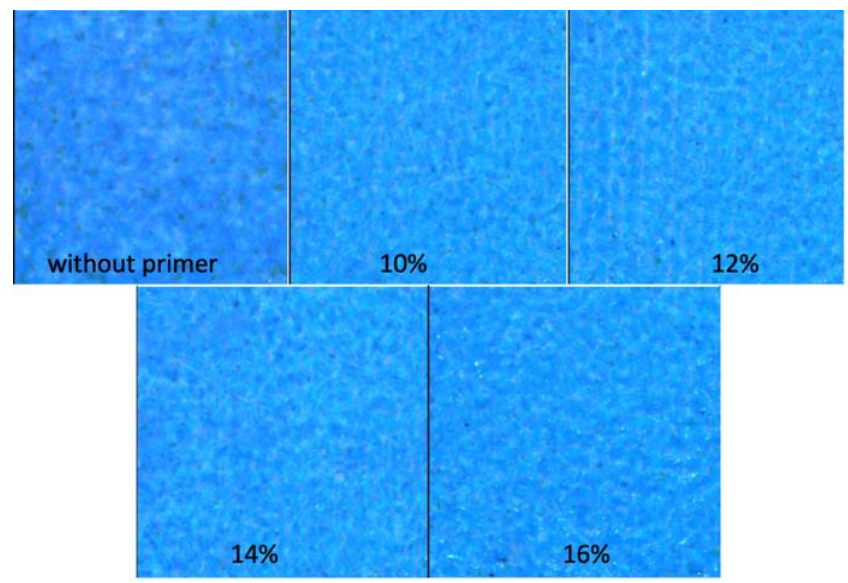

Fig. 4 Photographs (an increase of $\times 60$ ) of imprint fragment (Cyan) on offset paper without and with a primer $(10 \%, 12 \%, 14 \%, 16 \%)$ 


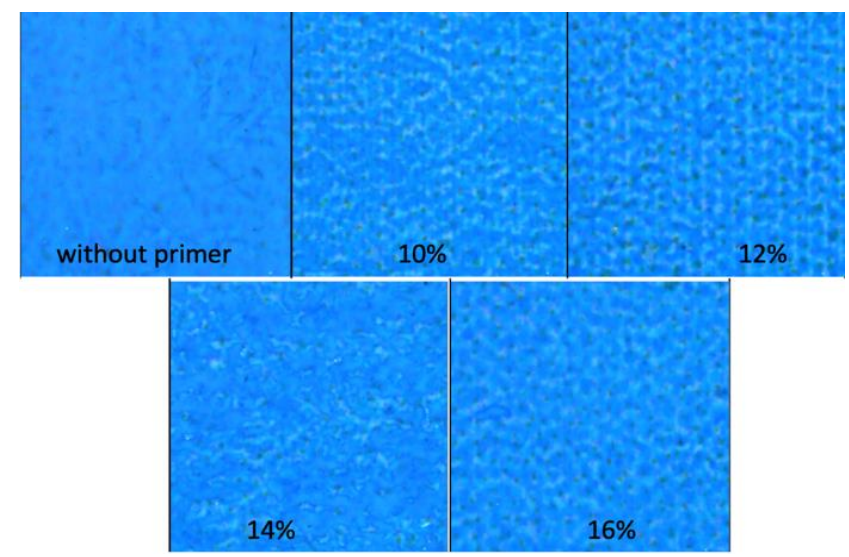

Fig. 5 Photographs (an increase of $\times 60$ ) of color imprint fragment (Cyan) on coated paper without and with a primer $(10 \%, 12 \%, 14 \%, 16 \%)$
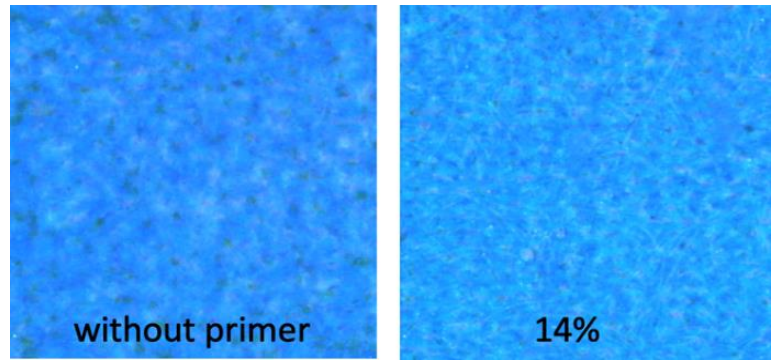

$\mathrm{a}$
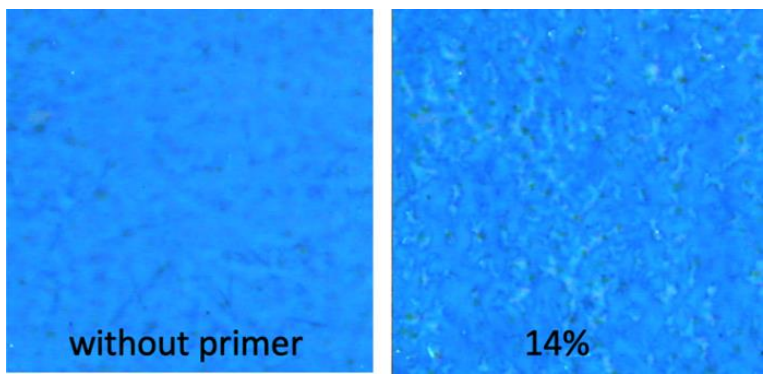

b

Fig. 6 Photographs comparison of offset and coated paper with and without a primer: a) offset paper; b) coated paper

As the analysis of photos shows, in the case of offset paper, the use of the primer improved the uniformity of the print. The mottle decreased (grain size unchanged) from $1.97 \%$ (offset paper without primer) to about $1-1.3 \%$ in the presence of a primer with a concentration $16 \%$ and $14 \%$. Offset paper at the expense of random distribution of fibers and pores between fibers and micropores absorbs ink not evenly, which leads to an increase in the phenomenon of spotting (mottle). In addition, offset paper without a primer is characterized by a greater absorption of ink, which manifests itself in reducing the optical density of the imprints of digital printing. In the case of coated paper, an increase in the mottle parameter was observed. This is obviously due to the fact that the presence of the primer has led to the fact that drops of ink in the process of drop inkjet printing did not penetrate deeply into the coated paper and remained in the upper layer of the primer, which caused a clear increase in saturation and optical density of the imprint.

\section{Conclusions}

Thus, as a result of the research, it has been confirmed that not only expensive paper of a special purpose can be used for a drop ink-jet digital printing. High-quality color imprints can also be obtained on ordinary offset and coated paper, coated before printing with special primers based on interpolymeric complexes of polyvinyl alcohol, which will provide sufficient optical density, contrast of images, and expand the possibilities of digital ink-jet printing.

\section{References}

1. Digital Printing. Technology and Printing Techniques of Océ Digital Printing Presses. 2006. Océ Printing Systems GmbH, 432 p.

2. Czichon, H.; Czichon, M. 2003. Reprographics and digital printing. Warszawa, Publishing house of the Warsaw University of Technology, 156 p. (in Polish).

3. Khadzhynova, S.; Jakucewicz, S. 2016. Digital printing methods. Lodz University of Technology Publishing House, 240 p. (in Polish).

4. Buczynski, L. 1997. Special print quality problems of ink-jet printers, International conference on digital printing technologies, IS\&T The Society for Imaging Science and Technology: 638-644.

5. Le, H. P. 1998. Progress and trends in ink-jet printing technology, IS\&T The Society for Imaging Science and Technology 42(1): 49-62.

6. Magdassi, S. 2010. The chemistry of ink-jet inks. World Scientific, $344 \mathrm{p}$.

7. Lavery, A.; Provost, J. Color-media interactions in ink-jet printing, International conference on digital printing technologies, IS\&T The Society for Imaging Science and Technology: 437-442.

8. Khadzhynova, S.; Jakucewicz, S.; Piłczyńska, K. 2017. Spray printing (ink-jet). Lodz University of Technology Publishing House, 212 p. (in Polish).

9. Pilczyńska, K. T. 2015. Impact of offset paper parameters on the quality of digital ink-jet printing, Warsaw University of Technology, PhD thesis, Warsaw.

10. Penetration Dynamics Analyzer Emtec PDA.C 02. Module PEAPrint Evenness Analyzer. [online] MPRA [accessed 9 Oct. 2019]. Available from Internet: https://www.emtec-

electronic.de/attachments/article/309/ModulePEA_eng.pdf.

11. Spektrodensitometer Seria 500 Operator's manual, Xrite. [online] MPRA [accessed 9 Oct. 2019].

Available from Internet: https://www.xrite.com//media/xrite/files/manuals_and_userguides/5/528500_500_series_operators_manual_en.pdf.

12. Kipphan, H. 2001. Handbook of print media. Springer, Berlin, Heidelberg, 1207 p.

13. ISO/IEC 13660: 2001 (E) Information Technology Office equipment - Measurement of image quality attributes for hardcopy output - Binary monochrome text and graphic images, $27 \mathrm{p}$.

14. Krasinskyi, V.; Suberlyak, O.; Antonuk, V.; Jachowicz, T. 2017. Rheological properties of compositions based on modified polyvinyl alcohol, Advances 
in Science and Technology Research Journal 11(3): 304-309.

https://doi.org/10.12913/22998624/76584.

S. Havenko, S. Khadzhynova, K. Olejnik, E. Kibirkštis, K. Vaitasius

\section{INFLUENCE OF PRIMERS ON THE OPTICAL CHARACTERISTICS OF INK-JET IMPRINTS}

\section{S u m mary}

The quality of ink-jet printing depends to a large extent on the technical characteristics of the selected equipment and the surface properties of the printed substrates. It is known that for digital printing it is necessary to use expensive paper with a special coating that determines the degree of gloss of the surface. Therefore, ordinary offset papers before ink-jet printing are covered with primers that ensure good fixation of pigment ink or dye on paper, a wide field of color coverage, characteristic gloss, which generally contribute to high quality of imprints. As you can see, the type of the substrate and the state of its surface has a very great influence on the quality of the imprints. Result of the research, it has been confirmed that not only expensive paper of a special purpose can be used for a drop ink-jet digital printing. High-quality color imprints can also be obtained on ordinary offset and coated paper, coated before printing with special primers based on interpolymeric complexes of polyvinyl alcohol, which will provide sufficient optical density, contrast of images, and expand the possibilities of digital ink-jet printing.

Keywords: ink-jet print, optical characteristics, primer, water penetration, graininess.

Received October 15, 2019 Accepted August 24, 2020 